\title{
INFORMATION AND COMMUNICATIONS TECHNOLOGY (ICT) AND THE SUSTAINABLE DEVELOPMENT GOALS (SDG)
}

\author{
Martin Grossman \\ Department of Management, Bridgewater State University \\ Bridgewater, MA. USA
}

\begin{abstract}
The UN's 2030 Agenda for Sustainable Development Goals (SDGs) includes a set of 17 goals, 169 specific targets and 232 indicators aimed at addressing the world's most pressing challenges (e.g. inequality, poverty, climate change). Information and communications technology (ICT) can play a key role in dealing with these issues. However, accelerated efforts from a wider array of stakeholders, including those in the private and civil sectors, will be necessary to make real progress. This paper explores ways in which ICT can help achieve the SDGs as well as frameworks for mapping ICT interventions to SDGs and methods for assessing progress towards achieving these goals.
\end{abstract}

\section{KEYWORDS}

ICT4D, Sustainable Development Goals (SDG), Information and Communications Technology (ICT)

\section{THE ROLE OF ICT IN ACHIEVING THE SUSTAINABLE DEVELOPMENT GOALS}

We are living in an era of profound technological transformation. Despite recent advances in technology, a significant percentage of the earth's inhabitants still live in abject poverty without the means necessary to meet basic human needs (e.g. food, clothing, healthcare, shelter). The number of people living in extreme poverty is still unacceptably high and there is still a huge gap between the 'haves' and 'have nots'. For the approximately 750 million people living in absolute poverty (defined by the World Bank as earning less than $\$ 1.90$ a day) everyday life remains a struggle. In 2000, the United Nations established the Millennium Development Goals (MDGs), comprising eight international development goals (e.g. halving extreme poverty rates, halting the spread of HIV/AIDS and providing universal primary education) for the year 2015. While some of the objectives were satisfied, there remains much work to tackle these challenges. A new, more ambitious framework was created by the United Nations General Assembly in 2015, consisting of 17 goals and a much more aggressive agenda, i.e. completion by 2030. Along with the 17 goals, the SDG framework consists of 169 specific targets and 232 indicators that can be used to measure progress. While the SDG goals and targets are well-intentioned, the issues involved are extremely complex requiring a massive effort with much greater urgency and prioritization at all levels. Problems of such gravity simply cannot be ameliorated with a 'business as usual' approach, especially within the timeframe specified by the U.N. Clearly a radical agenda is needed, one that includes not only involvement of international development organizations such as the U.N., but also governments, private businesses, and individuals. The enabler with perhaps the greatest potential to help level the playing field and reduce the chasm between the 'haves' and 'have nots' is information and communication technology (ICT). Studies have shown ICT to be highly correlated with accomplishment of developmental goals (Sachs, J. et al., 2016). Greater broadband connectivity and access to a wide range of information services can have a profound impact on many aspects of economic and human development. Paradoxically, ICT is not explicitly included as one of the UN's 17 SDGs and is only mentioned tangentially in a few of the associated indicators. ICT needs to be recognized as an essential aspect of the SDG agenda. There are many ways in which ICT can help deal with the planet's most pressing issues. Taking the first 5 SDGs as examples, we see some of the possible ways ICT can make a difference: SDG 1 No Poverty - provide timely and accurate information 
to help ensure equal rights to economic resources such as mobile banking and micro-credit; SDG 2 - No Hunger - reduce hunger and increase food security by providing farmers with market information, weather forecasts, advice on planting, harvesting and irrigation to increase yields; SDG 3 - Good Health - allow health workers access to information on health practices and diagnostic services and analytics to make projections about disease outbreaks; SDG 4 - Quality Education - allow students to access learning assets anywhere and anytime; SDG 5 - Gender Equality - allow women and girls access to information about reproductive health, community roles, sustainable livelihoods. The other SDGs, involving such areas as water, sanitation, industrialization/innovation, employment for all and ocean/marine resources, can also be advanced though ICT interventions. Emerging technologies such as artificial intelligence, Internet of Things, big data and blockchain, will provide numerous opportunities to confront the most difficult problems facing our planet.

The private sector, particularly ICT companies, can make significant contributions towards achieving the SDGs. The concept of business working for the good of society is not new; corporate social responsibility (CSR), a type of self-regulation for the private sector, has gained in popularity in recent years. Any meaningful progress towards attaining SDG goals will necessarily involve much greater collaboration between the private and civil sectors. While there has been little in the academic literature linking ICT's potential to the SDGs, there has been significant collaborative effort emanating from partnerships, including industry members, consulting companies, international development organizations and academic entities. Such partnerships are fast-tracking the SDG agenda by addressing the need for mapping, assessment, and investment. Examples are: (1) ICT-SDG Impact Assessment Framework (ASU Global Sustainability Solutions Services, 2017), a collaboration between Dell Computer and Arizona State University Global Sustainability Solutions Services which provides a process for mapping ICT solutions to the SDGs, (2) SDG ICT Playbook (NetHope, 2015) a collaboration between NetHope, Intel, CRS, Microsoft and CDW, which recommends areas for ICT investment for attainment of SDG goals, (3) ICT Development Goals Benchmark (Huawei, 2018), a collaboration between Huawei and SustainAbility which examines the degree to which ICT enables the SDGs in 49 countries, and (4) \#SystemTransformation_(GeSI \& Accenture Strategy, 2016), a collaboration between Global e-Sustainability Initiative (GesI) and Accenture Strategy, which identifies major gaps in achieving the SDGs through ICT.

\section{CONCLUSION}

ICT has an important role to play in accelerating the UN's agenda for sustainable development. Meaningful progress towards the 2030 goal will require greater prioritization at all levels and partnerships between government, industry and academic actors. Mapping and assessment methods are necessary to formalize the process and to measure progress towards attaining the goals. Future research will include formation of an analytical framework to examine the linkages between ICTs and SDGs and how progress in achieving the goals can be facilitated or accelerated through these technologies.

\section{REFERENCES}

ASU Global Sustainability Solutions Services 2017. The feasibility of mapping ICT initiatives to the UN Sustainability Development Goals. Available at: https://static.sustainability.asu.edu/giosMS-uploads/sites/15/2017/04/SDG-ICTFinal_Report_FINAL.pdf

GeSI \& Accenture Strategy 2016. \#SystemTransformation: How Digital Solutions Will Drive Progress Towards the Sustainable Development Goals. Summary Report. Available at: http://systemtransformationsdg.gesi.org/160608_GeSI_SystemTransformation.pdf

Huawei 2018. Accelerating SDGs through ICTs: 2018 Huawei Sustainability Development Goals Benchmark. Available at: https://www.huawei.com/minisite/gci/assets/files/Huawei_2018_SDG_report_en.pdf

NetHope 2015. SDG ICT Playbook: From Impact to Innovation. Available at: https://solutionscenter.nethope.org/assets/collaterals/NetHope_SDG_ICT_Playbook_Final.pdf

Sachs, J. et al. 2016. ICT \& SDGs: How information and communications technology can accelerate action on the Sustainable Development Goals. The Earth Institute: Columbia University. Available at: http://csd.columbia.edu/files/2016/10/ict-and-sdg-interim-report.pdf 